\title{
HUBUNGAN ANTARA PERFORMA KOMITE AUDIT DENGAN EARNINGS QUALITY
}

\author{
Nina Pertiwi \\ Akuntansi/Fakultas Bisnis dan Ekonomika \\ nina.lauw@gmail.com
}

\begin{abstract}
Abstrak-dengan berbagai skandal akuntansi terkait pelaporan keuangan, salah satu peran komite audit adalah untuk memastikan kualitas dari laporan keuangan yang diterbitkan perusahaan. Tujuan dari artikel ilmiah ini adalah untuk menguji hubungan antara performa komite audit yang diproksikan dengan 5 karakteristik komite audit (independensi, ukuran, keahlian di bidang finansial, aktivitas dan kepemilikan saham) dnegan earnings quality yang diproksikan dengan terjadinya earnings restatement pada perusahaan. Hasil penelitian ini menemukan bahwa performa komite audit yang dinilai dari sisi independensi memiliki hubungan negatif signifikan dengan terjadinya earnings restatement atau semakin independen komite audit akan semakin menjamin adanya earnings quality yang lebih tinggi. Sementara itu performa komite audit yang dinilai dari 4 karakteristik lainnya tidak ditemukan memiliki hubungan yang signifikan dengan earnings restatement. Studi ini berfokus pada perusahaan sektor jasa yang terdaftar di BEI dengan kode JASICA nomor 6199 dengan periode penelitian 2008-2010. Hasil dari penelitian ini menyediakan informasi yang berguna untuk profesi akuntansi, regulator, dan untuk keefektifan performa komite audit perusahaan.
\end{abstract}

Kata Kunci: komite audit, earnings quality, earnings restatement

Abstract- due to high number of accounting scandals related to financial reporting, one of audit committee's roles is to ensure the quality of financial statements issued by the firms. The purpose of this paper is to examine the association between audit committee characteristics (independence, size, financial expertise, activity and stock ownership) as proxies for audit committees performances with earnings restatement as proxies for earnings quality. This study found that audit committees performance related to their independences are significantly has a negative association with the occurrences of earnings restatements, in other words- the more independent an audit committees in perform their duties, they will ensure a higher quality of the reported earnings. However, the remaining four audit committee characteristics are not found to have a significant association with earnings restatement. This study focuses on service firms listed by Bursa Efek Indonesia (BEI) with JASICA code number 61-99 years of 2008-2010. The result of this study provides useful information for accounting profession, the regulators and for the effectiveness of firm's audit committees.

Keywords: audit committee, earnings quality, earnings restatement 


\section{PENDAHULUAN}

Laporan keuangan menyediakan informasi yang digunakan oleh stakeholders dan pengguna laporan keuangan sebagai dasar dalam pengambilan keputusan. Informasi penting yang biasa digunakan para pengguna laporan keuangan adalah laba yang dilaporkan perusahaan. Oleh karena itu kualitas laporan keuangan menjadi suatu hal yang penting untuk diperhatikan.

Salah satu peran komite audit adalah untuk memastikan kualitas dari laporan keuangan perusahaan. Namun dalam praktiknya selama ini banyak ditemukan penyimpangan-penyimpangan terkait pelaporan keuangan, seperti pada kasus Enron dan Worldcom, earnings management yang pernah dilakukan PT. Kimia Farma pada tahun 2002 lalu, serta kasus earnings restatement yang dilakukan Groupon Inc. pada awal 2012 lalu. Terjadinya berbagai kasus terkait pelaporan keuangan menyebabkan munculnya pertanyaan atas kualitas dari laporan keuangan yang diterbitkan oleh perusahaan, serta mengenai performa komite audit dalam menjamin kualitas dari laba yang dilaporkan perusahaan.

Banyak peraturan yang mengatur mengenai komite audit, salah satunya adalah surat edaran BAPEPAM KEP-29/PM/2004 yang menerbitkan peraturan No.IX.i.5 mengenai pembentukan dan pedoman pelaksanaan kerja komite audit. Tujuan dari peraturan komite audit ini adalah untuk memastikan agar komite audit di Indonesia dapat berjalan lebih efektif dan efisien.

Banyak studi terdahulu yang telah meneliti performa komite audit dalam menjamin kualitas laba perusahaan, baik dinilai dari aktivitas earnings management (Rahman et al., 2006; Kang et al., 2011; Yang dan Krishnan, 2005; dan Felo et al., 2003; Becker et al., 1998) dan earnings restatement (Lin et al., 2006; Abbott et al.,2004). Performa komite audit dinilai dengan melihat keefektifan 5 karakteristik komite audit yaitu dari sisi independensi, ukuran, keahlian di bidang finansial, aktivitas (diproksikan dengan frekuensi rapat) serta kepemilikan saham komite audit (Lin et al., 2006). 
Isu-isu terkait dengan earnings restatement menjadi menarik karena cukup banyak perusahaan yang melakukannya sehingga dijadikan proksi dalam menilai earnings quality dalam penelitian ini. Lin et al. (2006) meneliti 212 perusahaan publik USA yang melakukan restatement, menemukan bahwa performa komite audit telah menjadi subjek yang semakin menarik karena meningkatnya perhatian terhadap kualitas dari proses pelaporan keuangan perusahaan. Banyak studi terdahulu meneliti performa komite audit melalui karakteristiknya sebagai penentu keefektifannya dalam menentukan kualitas laba yang dilaporkan perusahaan.

BAPEPAM KEP-29/PM/2004 mensyaratkan agar komite audit di Indonesia harus independen, dimana merupakan anggota dari luar direksi, dan tidak memiliki hubungan/afiliasi langsung maupun tidak langsung dengan perusahaan. Penelitian Abbott et al. (2004) menyatakan bahwa terdapat hubungan yang negatif antara keterjadian earnings restatement dan komite audit yang hanya terdiri dari direktur independen. Penelitian oleh Abbott dan Parker (2000) dalam Kang et al. (2011) menemukan bahwa perusahaan dengan komite audit yang semuanya hanya terdiri dari luar direksi yang tidak terkait dengan manajemen perusahaan jarang menerima sanksi dari SEC terkait dengan pelaporan keuangan. Hasil studi empiris lainnya yang secara umum menunjukkan bahwa independensi komite audit berhubungan negatif dengan terjadinya financial fraud (Beasley, 1996; Dechow et al, 1995 dalam Rahman et al., 2006). Untuk menguji hubungan antara independensi komite audit dan earnings quality maka studi ini menguhi $\mathrm{H} 1$ :

H1 : Terdapat hubungan negatif antara independensi komite audit dengan terjadinya earnings restatement

BAPEPAM KEP-29/PM/2004 mensyaratkan agar komite audit terdiri dari 3 orang dengan 1 komisaris independen sebagai ketua dan 2 orang anggota dari luar direksi agar dapat berjalan efektif. Lin et al. (2006) menemukan bahwa ukuran komite audit berhubungan negatif dengan earnings restatement, dimana 
perusahaan dengan komite audit yang terdiri dari paling tidak 4 orang akan kurang mengalami earnings restatement. Yang dan Khrisnan (2005) dalam Lin et al.(2006) menemukan bahwa ukuran komite audit berhubungan negatif dengan earnings management. Felo et al. (2003) dalam Kang et al. (2011) juga melaporkan bahwa semakin besar jumlah anggota komite audit akan meningkatkan kualitas pelaporan keuangan. Untuk menguji hubungan antara ukuran komite audit dengan earnings quality, penelitian ini mengembangkan hipotesis:

H2 : Terdapat hubungan negatif antara ukuran komite audit dan terjadinya earnings restatement.

BAPEPAM KEP-29/PM/2004 mensyaratkan agar anggota komite audit harus memiliki keahlian di bidang keuangan dan akuntansi, yang dilihat melalui latar belakang pendidikan serta pengalamannya di bidang tersebut. Xie et al. (2003) dalam Rahman et al. (2006) melaporkan bahwa jumlah rapat komite audit berhubungan secara negatif dengan earnings management dan bahwa komite yang mengadakan rapat secara teratur dapat mengawasi manajemen dengan lebih baik. Lin dan Hwang (2010) serta Vafeas (2005) dalam Kang et al. (2011) menemukan adanya hubungan negatif antara frekuensi meeting komite audit dengan earnings management. Kang et al. (2011) membuktikan bahwa frekuensi rapat komite audit berhubungan dengan berkurangnya tingkat aggressive (income-increasing) earnings management. Untuk menguji hubungan antara keahlian komite audit di bidang finansial dengan earnings quality, penelitian ini mengembangkan hipotesis:

H3 : Terdapat hubungan negatif antara keahlian financial anggota komite audit dengan terjadinya earnings restatement.

Rahmat et al. (2009) berdasarkan panduan Best Practice Code of Corporate Governance Malaysia mensyaratkan komite audit untuk mengadakan rapat paling tidak sebanyak 3 kali dalam 1 tahun. Xie et al. (2003) dalam Rahman et al. (2006) melaporkan bahwa jumlah rapat komite audit 
berhubungan secara negatif dengan earnings management dan bahwa komite yang mengadakan rapat secara teratur dapat mengawasi manajemen dengan lebih baik. Lin dan Hwang (2010) serta Vafeas (2005) dalam Kang et al. (2011) menemukan adanya hubungan negatif antara frekuensi meeting komite audit dengan earnings management. Kang et al. (2011) membuktikan bahwa frekuensi rapat komite audit berhubungan dengan berkurangnya tingkat aggressive (income-increasing) earnings management. Untuk menguji hubungan antara aktivitas komite audit dengan earnings quality, penelitian ini mengembangkan hipotesis:

H4 : Terdapat hubungan negatif antara frekuensi pertemuan (rapat) komite audit dengan terjadinya earnings restatement

Peraturan BAPEPAM KEP-29/PM/2004 mensyaratkan bahwa komite audit tidak diperkenankan untuk memiliki saham dalam perusahaan secara langsung maupun tidak langsung. Kepemilikan saham oleh komite audit juga memiliki hubungan dengan keterjadian earnings restatement. penelitian oleh Choi et al. (2004) dalam Rahman et al. (2006) menemukan bahwa ketika anggota komite audit memiliki saham dalam perusahaan, mereka kurang memiliki insentif untuk mencegah earnings management. Yang dan Krishnan (2005) dalam Lin et al. (2006) menemukan bahwa kepemilikan saham oleh direksi independen maupun anggota komite audit non-independen akan berhubungan positif dengan terjadinya earnings management. Namun Vafeas (2005) dalam Kang et al. (2011) berpendapat bahwa semakin tinggi kepemilikan saham oleh anggota komite audit, semakin memotivasi mereka untuk mengawasi proses pelaporan keuangan dengan lebih efektif dan demikian akan meningkatkan earnings quality. Untuk menguji hubungan antara independensi komite audit dan earnings quality maka studi ini menguhi H1:

H5 : Terdapat hubungan yang signifikan antara kepemilikan saham anggota komite audit dengan terjadinya earnings restatement. 


\section{METODE PENELITIAN}

\section{Pemilihan Sampel}

Untuk mendapatkan sampel yang digunakan dalam penelitian ini, pertama-tama dilakukan riset pendahuluan pada seluruh laporan keuangan perusahaan-perusahaan yang terdaftar di BEI tahun 2011 untuk menemukan perusahaan pada sektor mana yang paling banyak melakukan earnings restatement terhadap laporan keuangan periode sebelumnya (tahun 2010). Perusahaan yang melakukan earnings restatement tahun 2010 diketahui dari keterangan dalam laporan keuangan 2011 yang mencantumkan bahwa laba pada laporan keuangan 2010 telah disajikan kembali. Setelah dilakukan riset pendahuluan, ditemukan bahwa perusahaan yang paling banyak melakukan earnings restatement ada pada perusahaan sektor jasa (tersier).

Tabel 1

Riset pendahuluan perusahaan yang melakukan earnings restatement

\begin{tabular}{|l|l|l|}
\hline SEKTOR & KODE & JUMLAH \\
JASICA & RESTATEMENT \\
\hline Primary & $11-29$ & 8 \\
\hline Secondary (Manufactur) & $31-59$ & 17 \\
\hline Tersier (Service) & $61-99$ & 41 \\
\hline
\end{tabular}

Setelah mengetahui sektor yang perusahaannya paling banyak melakukan earnings restatement adalah sektor jasa, maka berdasarkan namanama perusahaan yang tertera di fact book setiap tahunnya, dilakukan pencarian nama-nama perusahaan yang melakukan earnings restatement pada tahun 2008, 2009, serta 2010 pada sektor tersebut. Klasifikasi sektor jasa BEI yang digunakan dalam penelitian ini adalah berdasarkan pada kode JASICA nomor 61-99, yaitu property, real estate \& building construction; infrastructure, utilities \& transportation; finance; dan trade, service \& investment. Setelah mengeluarkan perusahaan yang tidak memenuhi syarat, ditemukan ada 60 perusahaan yang melakukan earnings restatement dengan rincian seperti Tabel 2. 
Tabel 2

Riset pendahuluan perusahaan yang melakukan earnings restatement pada sector jasa

\begin{tabular}{|l|l|l|l|}
\hline TAHUN & $\begin{array}{l}\text { TOTAL PERUSAHAAN } \\
\text { SEKTOR JASA }\end{array}$ & $\begin{array}{l}\text { TIDAK MEMENUHI } \\
\text { KRITERIA }\end{array}$ & $\begin{array}{l}\text { JUMLAH } \\
\text { RESTATEMENT }\end{array}$ \\
\hline 2008 & 220 & 15 & 10 \\
\hline 2009 & 225 & 12 & 8 \\
\hline 2010 & 234 & 11 & 41 \\
\hline Total & $\mathbf{6 7 9}$ & $\mathbf{3 8}$ & $\mathbf{6 0}$ \\
\hline
\end{tabular}

Dari 60 perusahaan yang ditemukan melakukan earnings restatement ditemukan bahwa hanya 46 perusahaan diantaranya yang memiliki annual report dengan keterangan lengkap yang dibutuhkan dalam penelitian ini, sedangkan 14 lainnya tidak memiliki keterangan yang lengkap mengenai variabel yang dibutuhkan dalam penelitian ini. Dengan adanya ke-46 perusahaan yang melakukan earnings restatement ini kemudian dilakukan pencarian matched sample, yaitu perusahaan yang berada pada sub-sektor yang sama atau mendekati yang memiliki jumlah total asset yang mirip dengan ke-46 perusahaan tersebut. Dengan ditemukannya matched sample, maka total sampel yang digunakan dalam penelitian ini adalah sebanyak 92 perusahaan (daftar sampel perusahaan yang digunakan dapat dilihat pada Lampiran).

\section{Model Penelitian}

Penelitian ini menggunakan model regresi logistic karena variabel dependen earnings restatement (RESTMT) merupakan variabel dummy yang akan bernilai "1" apabila perusahaan melakukan earnings restatement pada tahun penelitian, dan bernilai " 0 ” apabila perusahaan tidak melakukan earnings restatement. variabel independen performa komite audit yang diproksikan dengan ACINDD, ACSIZED, ACEXPD, ACMEETD, dan ACOWNPT merupakan karakteristik komite audit yang digunakan untuk menguji hipotesis penelitian. Variabel lain yang diikutsertakan adalah variabel kontrol terkait kualitas audit dan karakteristik keuangan perusahaan yang dapat mempengaruhi 
keputusan manajemen untuk melakukan manipulasi terhadap laba. Model dalam penelitian ini adalah sebagai berikut:

\section{RESTMT $=\beta_{0}+\beta_{1}$ ACINDD $+\beta_{2}$ ACSIZED $+\beta_{3}$ ACEXPD $+\beta_{4} A C M E E T D+\beta$ ${ }_{5} \mathrm{ACOWNPT}+\beta_{6} \mathrm{BIG} 4+\beta_{7} \mathrm{AUDITEN}+\beta_{8} \mathrm{CFO}+\beta_{9} \mathrm{ABSCFO}+\beta_{10}$ $\mathrm{ACC}+\beta_{11} \mathrm{ABSACC}+\beta_{12} \mathrm{MKRTX}+\beta_{13} \mathrm{LOSS}+\beta_{14} \mathrm{MKBKF}+\beta_{15} \mathrm{LE}$ VERG $+\beta_{16}$ FINACQ+ $+\beta_{17}$ LNMVE+ $\varepsilon$}

ACINDD (Audit committee independence) bernilai “1” jika anggota komite audit independen, selain itu maka nilainya "0". ACSIZED (Audit Committee size) bernilai “ 1 ” jika komite audit terdiri dari paling tidak 4 anggota, jika kurang maka bernilai “0”. ACEXPD (Audit Committee Expertise, bernilai “1” jika paling tidak salah satu anggota komite audit memiliki keahlian finansial, selain itu maka bernilai “0”. ACMEETD (Audit Committee Meeting) bernilai “1” jika paling tidak komite audit mengadakan rapat 4x dalam tahun fiskal, selain itu bernilai "0". ACOWNPT (Audit Committee Stock Ownership) persentase saham beredar yang dimiliki oleh anggota komite audit.

Penelitian ini menyertakan 2 variabel sebagai proksi kualitas audit. Studi terdahulu menyatakan bahwa auditor BIG-4 dapat mendeteksi aktivitas earnings management lebih baik dibandingkan auditor non-BIG-4 (Becker et al., 1998). BIG4(Big-4 Auditors) bernilai “1” jika perusahaan diaudit oleh Big4, jika tidak maka bernilai “0”. Variabel lainnya adalah AUDITEN (Audit tenure), merupakan jumlah tahun auditor mengaudit perusahaan tersebut.

Penelitian ini juga menyertakan beberapa variabel yang biasanya digunakan dalam penelitian terdahulu untuk mengendalikan factor lain yang dapat mempengaruhi insentif manajemen untuk memanipulasi laba : arus kas operasi dibagi dengan total asset (CFO), niali absolute dari CFO (ABSCFO); total akrual dibagi dengan total asset (ACC), dan nilai absolute ACC (ABSACC); Annual Market returns (MKRTX) dan LOSS sebagai variabel indicator rugi perusahaan, dimana jika perusahaan mengalami rugi pada tahun fiskal maka bernilai “1", jika tidak maka nilainya "0". Selain itu growth prospects yang diukur dari Market-to-book ratio (MKBKF) juga diikutsertakan 
dalam penelitian ini. Rasio total utang atas total asset atau leverage (LEVERG), dan indicator variabel pendanaan (FINACQ) yang bernilai "1" jika perusahaan menerbitkan ekuitas atau debt securities selama tahun fiskal, selain itu maka nilainya "0" juga disertakan dalam penelitian ini. Dan kemudian penelitian ini juga mengendalikan ukuran perusahaan dengan mengukur natural logaritma dari market value of equity (LNMVE)

\section{HASIL DAN PEMBAHASAN}

\section{Statistik Deskriptif}

Hasil statistic deskriptif penelitian ini adalah sebagai berikut:

Tabel 3

Descriptive Statistics untuk variabel dummy independensi komite audit

\begin{tabular}{|l|l|l|l|l|l|l|}
\hline & \multicolumn{2}{|c|}{$\begin{array}{c}1 \\
\text { (independen) }\end{array}$} & \multicolumn{2}{c|}{$\begin{array}{c}0 \\
\text { (tidak } \\
\text { independen) }\end{array}$} & \multicolumn{2}{c|}{ Total } \\
\hline Earnings restatement & 31 & $67,39 \%$ & 15 & $32,61 \%$ & 46 & $100 \%$ \\
\hline Non-Earnings Restatement & 43 & $93,48 \%$ & 3 & $6,52 \%$ & 46 & $100 \%$ \\
\hline
\end{tabular}

Sumber: hasil olah data

Tabel 4

Descriptive Statistics untuk variabel dummy ukuran komite audit

\begin{tabular}{|l|l|l|l|l|l|l|}
\hline & \multicolumn{2}{|c|}{$\begin{array}{c}1 \\
\text { (ukuran efektif) }\end{array}$} & \multicolumn{2}{c|}{$\begin{array}{c}0 \\
\text { (ukuran tidak } \\
\text { efektif) }\end{array}$} & \multicolumn{2}{c|}{ Total } \\
\hline Earnings restatement & 46 & $100 \%$ & 0 & $0 \%$ & 46 & $100 \%$ \\
\hline Non-Earnings Restatement & 44 & $95,65 \%$ & 2 & $4,35 \%$ & 46 & $100 \%$ \\
\hline
\end{tabular}

Sumber: hasil olah data

Tabel 5

Descriptive Statistics untuk variabel dummy keahlian komite audit di bidang finansial

\begin{tabular}{|l|l|l|l|l|l|l|}
\hline & \multicolumn{2}{|c|}{$\begin{array}{c}1 \\
\text { (ahli bidang } \\
\text { financial) }\end{array}$} & \multicolumn{2}{|c|}{$\begin{array}{c}0 \\
\text { (tidak ahli } \\
\text { bidang financial) }\end{array}$} & \multicolumn{2}{|c|}{ Total } \\
\hline Earnings restatement & 42 & $91,30 \%$ & 4 & $8,70 \%$ & 46 & $100 \%$ \\
\hline Non-Earnings Restatement & 43 & $93,48 \%$ & 3 & $6,52 \%$ & 46 & $100 \%$ \\
\hline
\end{tabular}

Sumber: hasil olah data 
Tabel 6

Descriptive Statistics untuk variabel dummy aktivitas komite audit (frekuensi rapat)

\begin{tabular}{|l|c|l|l|l|l|l|}
\hline & \multicolumn{2}{|c|}{$\begin{array}{c}1 \\
\text { (rapat } \geq 3 \text { kali) }\end{array}$} & \multicolumn{2}{|c|}{$\begin{array}{c}0 \\
\text { (rapat <3 kali }\end{array}$} & \multicolumn{2}{c|}{ Total } \\
\hline Earnings restatement & 42 & $91,30 \%$ & 4 & $8,70 \%$ & 46 & $100 \%$ \\
\hline Non-Earnings Restatement & 41 & $89,13 \%$ & 5 & $10,87 \%$ & 46 & $100 \%$ \\
\hline
\end{tabular}

Sumber: hasil olah data

Tabel 7

Descriptive Statistics untuk variabel dummy audit quality

\begin{tabular}{|l|l|l|l|l|l|l|}
\hline & \multicolumn{2}{|c|}{$\begin{array}{c}1 \\
\text { (auditor BIG-4) }\end{array}$} & \multicolumn{2}{c|}{$\begin{array}{c}0 \\
\text { (auditor non- } \\
\text { BIG-4) }\end{array}$} & \multicolumn{2}{c|}{ Total } \\
\hline Earnings restatement & 24 & $51,17 \%$ & 22 & $47,83 \%$ & 46 & $100 \%$ \\
\hline Non-Earnings Restatement & 17 & $36,96 \%$ & 29 & $63,04 \%$ & 46 & $100 \%$ \\
\hline
\end{tabular}

Sumber: hasil olah data

Tabel 8

Descriptive Statistics untuk variabel dummy LOSS

\begin{tabular}{|l|l|l|l|l|l|l|}
\hline & \multicolumn{2}{|c|}{$\begin{array}{c}1 \\
\text { (loss) }\end{array}$} & \multicolumn{2}{|c|}{$\begin{array}{c}0 \\
\text { (profit) }\end{array}$} & \multicolumn{2}{c|}{ Total } \\
\hline Earnings restatement & 10 & $21,74 \%$ & 36 & $78,26 \%$ & 46 & $100 \%$ \\
\hline Non-Earnings Restatement & 4 & $8,70 \%$ & 32 & $91,30 \%$ & 46 & $100 \%$ \\
\hline
\end{tabular}

Sumber: hasil olah data

Tabel 9

Descriptive Statistics untuk variabel dummy financial indicator

\begin{tabular}{|l|c|c|c|c|c|l|}
\hline & \multicolumn{2}{|c|}{$\begin{array}{c}1 \\
\text { (menerbitkan } \\
\text { sekuritas) }\end{array}$} & \multicolumn{2}{|c|}{$\begin{array}{c}0 \\
\text { (tidak } \\
\text { menerbitkan } \\
\text { sekuritas) }\end{array}$} & \multicolumn{2}{|c|}{ Total } \\
\hline Earnings restatement & 21 & $45,65 \%$ & 25 & $54,35 \%$ & 46 & $100 \%$ \\
\hline Non-Earnings Restatement & 16 & $34,78 \%$ & 30 & $65,22 \%$ & 46 & $100 \%$ \\
\hline
\end{tabular}

Sumber : hasil olah data

Statistik deskriptif yang digunakan untuk variabel-variabel dalam penelitian ini adalah perhitungan rata-rata, median, standar deviasi, nilai maksimum dan nilai minimum. Data statistik deskriptif diolah menggunakan program SPSS 18.0 for Windows. Berikut ini adalah hasil perhitungan statistik deskriptif untuk variabel lainnya: 
Tabel 10

Descriptive Statistics

(untuk sampel perusahaan yang melakukan earnings restatement)

\begin{tabular}{|l|l|r|r|r|r|}
\hline & $\mathrm{N}$ & \multicolumn{1}{|c|}{ Minimum } & Maximum & Mean & \multicolumn{1}{c|}{ Std. Deviation } \\
\hline ACOWNPT & 46 &, 0000000 &, 0001324 &, 000002881 &, 0000195240 \\
AUDITEN & 46 & 1 & 6 & 3,07 & 1,902 \\
CFO & 46 &,- 1063510000 &, 5717522500 &, 067501760276 &, 1297159222571 \\
ABSCFO & 46 &, 0006410932 &, 5717522500 &, 088847502576 &, 1158216955812 \\
ACC & 46 &,- 8200826600 & 9,4620690000 &, 127988934397 & 1,4202565337460 \\
ABSACC & 46 &, 0004593178 & 9,4620690000 &, 323697105356 & 1,3880798098615 \\
MKRTX & 46 &,- 827586230 & 12,500000000 &, 81254377643 & 2,042117647743 \\
MKBKF & 46 &, 10000000 & 132,00000000 & 11,2360048772 & 24,52919238275 \\
LEVERG & 46 &, 0009088810 &, 9391030700 &, 587449347043 &, 2848386994403 \\
LNMVE & 46 & 24,6085 & 34,9872 & 28,240472 & 2,3939297 \\
Valid N (listwise) & 46 & & & & \\
\hline
\end{tabular}

Sumber : output SPSS

Tabel 11

Descriptive Statistics

(untuk sampel perusahaan yang tidak melakukan earnings restatement)

\begin{tabular}{|l|l|r|r|r|r|}
\hline & $\mathrm{N}$ & \multicolumn{1}{c|}{ Minimum } & Maximum & Mean & Std. Deviation \\
\hline ACOWNPT & 46 &, 00000 &, 00002 &, 0000004 &, 00000259 \\
AUDITEN & 46 & 1 & 6 & 3,07 & 1,781 \\
CFO & 46 &,- 1755350100 &, 2340024900 &, 056315034832 &, 0784605289521 \\
ABSCFO & 46 &, 0001859764 &, 2340024900 &, 072815932181 &, 0630708108080 \\
ACC & 46 &,- 2353066000 &, 3664740000 &,- 019880038821 &, 0998219841802 \\
ABSACC & 46 &, 0002149182 &, 3664740000 &, 067152786418 &, 0758862259156 \\
MKRTX & 46 &,- 878571450 & 4,084746000 &, 44339965652 &, 948514706570 \\
MKBKF & 46 &, 1140000 & $5,0000000 \mathrm{E} 3$ & 114,220675880 & 736,4380530160 \\
LEVERG & 46 &, 015034251 &, 938202440 &, 56173384928 &, 296101035216 \\
LNMVE & 46 & 19,5391 & 32,4948 & 27,601388 & 2,4234708 \\
Valid N (listwise) & 46 & & & & \\
\hline
\end{tabular}

Sumber: oputput SPSS 


\section{Hasil Multivariatif}

Tabel 12 memuat hasil regresi logistic untuk menemukan hasil uji atas hipotesis dalam penelitian ini.

Tabel 12

Wald Test

Variables in the Equation

\begin{tabular}{|ll|r|r|r|r|r|r|}
\hline & \multicolumn{1}{|c|}{ B } & \multicolumn{1}{c|}{ S.E. } & Wald & df & \multicolumn{1}{c|}{ Sig. } & Exp(B) \\
\hline Step $1^{\text {a }}$ & ACINDD & $-1,856$ &, 774 & 5,746 & 1 &, 017 &, 156 \\
& ACSIZED & 21,146 & 28187,927 &, 000 & 1 &, 999 & $1,527 \mathrm{E} 9$ \\
ACEXPD & $-1,425$ & 1,019 & 1,955 & 1 &, 162 &, 241 \\
ACMEETD &,- 714 &, 911 &, 616 & 1 &, 433 &, 489 \\
ACOWNPT & 179,971 & 25383,858 &, 000 & 1 &, 994 & $1,447 \mathrm{E} 78$ \\
BIG4 &, 511 &, 658 &, 603 & 1 &, 437 & 1,667 \\
AUDITEN &, 005 &, 148 &, 001 & 1 &, 972 & 1,005 \\
CFO & $-4,571$ & 5,622 &, 661 & 1 &, 416 &, 010 \\
ABSCFO & $-4,134$ & 6,971 &, 352 & 1 &, 553 &, 016 \\
ACC & $-6,410$ & 5,354 & 1,434 & 1 &, 231 &, 002 \\
ABSACC & 7,141 & 5,507 & 1,681 & 1 &, 195 & 1262,387 \\
MKRTX &, 211 &, 198 & 1,132 & 1 &, 287 & 1,235 \\
LOSS &, 560 &, 966 &, 336 & 1 &, 562 & 1,751 \\
MKBKF &,- 001 &, 002 &, 139 & 1 &, 709 &, 999 \\
LEVERG &,- 227 & 1,020 &, 050 & 1 &, 823 &, 797 \\
FINACQ &, 133 &, 570 &, 055 & 1 &, 815 & 1,142 \\
LNMVE &, 143 &, 137 & 1,094 & 1 &, 296 & 1,154 \\
Constant & $-22,174$ & 28187,927 &, 000 & 1 &, 999 &, 000 \\
\hline
\end{tabular}

a. Variable(s) entered on step 1: ACINDD, ACSIZED, ACEXPD, ACMEETD, ACOWNPT, BIG4, AUDITEN, CFO, ABSCFO, ACC, ABSACC, MKRTX, LOSS, MKBKF, LEVERG, FINACQ, LNMVE. Sumber: outpus SPSS

$\mathrm{H}_{1} \quad$ menyatakan terdapat hubungan negative signifikan antara independensi komite audit dengan terjadinya earnings restatement. Seperti yang ditunjukkan pada Tabel 12, hipotesis ini diterima dengan melihat pada nilai koefisien negatif sebesar 1,856 dengan nilai signifkansi $0,017<\alpha(0,05)$. 
Dengan adanya hubungan negatif signifikan antara independensi komite audit dengan terjadinya earnings restatement maka semakin independen suatu komite audit, maka komite audit semakin efektif dan efisien dalam menjalankan tugasnya, serta kualitas dari laba yang dilaporkan badan usaha juga akan lebih baik. $\mathrm{H}_{2}$ memprediksi terdapat hubungan negatif signifikan antara ukuran komite audit dengan terjadinya earnings restatement. Seperti yang tertera pada Tabel 12, hipotesis ini ditolak karena nilai signifikansinya yang lebih besar $5 \%$. $\mathrm{H}_{3}$ memprediksi bahwa terdapat hubungan negatif signifikan antara keahlian financial anggota komite audit dengan terjadinya earnings restatement. $\mathrm{H}_{3}$ ditolak karena walaupun keahlian anggota komite audit di bidang finansial memiliki hubungan negatif dengan terjadinya earnings restatement namun hubungannya tidak signifikan $(\alpha>5 \%) . \mathrm{H}_{4}$ memprediksi bahwa terdapat hubungan negatif antara frekuensi pertemuan (rapat) komite audit dengan terjadinya earnings restatement. Namun hasil regresi menunjukkan bahwa tidak ada hubungan yang signifikan antara frekuensi rapat komite audit dengan terjadinya earnings restatement, sehingga $\mathrm{H}_{4}$ ditolak. $\mathrm{H}_{5}$ memprediksi adanya hubungan signifikan antara kepemilikan saham anggota komite audit dengan terjadinya earnings restatement. Hasil regresi pada Tabel 12 menunjukkan bahwa hipotesis ini ditolak. Secara keseluruhan, hasil pada Tabel 12 hanya mendukung $\mathrm{H}_{1}$ bahwa ada hubungan negative signifikan antara terjadinya earnings restatement dengan independensi komite audit. 


\section{KESIMPULAN DAN SARAN}

Penelitian ini menguji hubungan antara performa komite audit yang diproksikan melalui karakteristik komite audit dengan earnings quality yang diproksikan dengan terjadinya earnings restatement. Hasil yang disajikan dalam Tabel 12 mendukung hipotesis bahwa komite audit yang independen dapat menjalankan tugas dan tanggung jawabnya dengan lebih baik dan efisien, sehingga performanya lebih baik dalam menjamin kualitas dari laba yang dilaporkan perusahaan. Hal ini disebabkan karena komite audit yang independen akan lebih objektif dalam pekerjaannya, sehingga terlepas dari pengaruh-pengaruh manajemen maupun pengaruh lainnya yang dapat mempengaruhi performanya dalam proses pelaporan keuangan perusahaan. Hasil ini sesuai dengan pernyataan SEC (1999) bahwa semakin independen anggota komite audit suatu perusahaan, maka kemampuannya untuk memastikan diterbitkannya laporan keuangan yang lebih berkualitas oleh manajemen. Sementara itu hipotesis terkait performa komite audit dari 4 karakteristik lainnya tidak dapat diterima. Dengan kata lain, penelitian ini membuktikan bahwa performa komite audit yang dinilai dari karakteristik komite audit lainnya (ukuran, keahlian di bidang finansial, aktivitas, dan kepemilikan saham) tidak memiliki hubungan dengan kualitas dari laba yang dilaporkan perusahaan. Hasil ini ditemukan setelah mengendalikan beberapa variabel yang sering digunakan dalam penelitian terdahulu untuk mengendalikan factor lain yang dapat mempengaruhi insentif manajemen untuk memanipulasi laba yang dilaporkan. Namun, penelitian ini membatasi objek pada perusahaan sektor jasa BEI saja, serta penentuan aktivitas earnings restatement belum dibatasi berdasarkan alasan dilakukannya. Sehingga diharapkan studi pada penelitian berikutnya yang menguji hal serupa dapat menambah sektor yang menjadi objek penelitian serta membatasi perusahaan yang melakukan earnings restatement karena alasan dengan konteks negatif. 


\section{DAFTAR PUSTAKA}

Abbott, L.J., Park, Y. and Parker, S. (2000), "The effects of audit committee activity and independence on corporate fraud", Managerial Finance, Vol. 26, pp. 55-67.

Abbott, L.J., Parker, S. and Peters, G.F. (2004), "Audit committee characteristics and restatements", Auditing: A Journal of Practice \& Theory, Vol. 23, pp. 69-87.

Abdullah, Nahar Shamsul., Yusof,N.Z.M.,Naimi, Moh.,Moh.Nor.,2010, "Financial restatements and corporate governance among malaysian listed companies", Managerial Auditing Journal-Emerald Vol.25 No.6,2010 pp 526-552.

Abdelghany, Khaled ElMoatasem. (2005), "Measuring the quality of earnings", Managerial Auditing Journal-Emerald Vol 20 pp. 10011015.

Barragato, Charles A., Ariel Markelevich. (2008), "Earnings quality following corporate acquisitions", Managerial Auditing Journal-Emerald Vol. 34. Pp. 304-315.

BAPEPAM-Peraturan Nomor IX.I.5: Pembentukan dan pedoman pelaksanaan kerja komite audit. 24 September 2004.

Becker, Connie L., Defond, Mark L., Jiambalvo James, K.R. Subramanyam. (1998), "The effect of audit quality on earnings management", Contemporary Accounting Research Vol. 15 pp.1-24.

Bernardin, John H., \& Russel, Joyce E.A. (1993). Human resources management an experintal approach. Singapura: McGraw-Hill, Inc.

Burgstahler, David, Ilia Dichev. (1997), "Earnings management to avoid earnings decreases and losses", Journal of Accounting and EconomicsElsevier Vol 24 pp. 99-126

Chi, Hsin-Yi, Weng, Tzu-Ching, Cheng-Hwai Liou. (2011), “Accounting restatement and managerial legal liability coverage", Procedia-Social and Behavioral Sciences-Elsevier Vol. 25 pp. 147-158. 
Dechow,Patricia.,WeiliGe. (2010), "Understanding earnings quality:are view of the proxies, their determinants and their consequences", Journal of Accounting and Economics-Emerald Vol. 50. 2010. Pp 344401

DeZoort, F.T., Hermanson, D.R., Archambeault, D.S. and Reed, S.A. (2002), "Audit committee effectiveness:a synthesis of the empirical audit committee literature", Journal of Accounting Literature, Vol. 21, pp. $38-75$.

Djalil, sofyan A 2000. Good corporate governance. Komite nasional corporate governance

Efferin, S., Darmaji, S.,dan Tan,Y., 2008. Metode Penelitian Akuntansi Mengungkap Fenomena dengan Pendekatan Kuantitatif dan Kualitatif. Yogyakarta:Graha Ilmu.

Ghozali, Imam. 2011. Analisis Multivariative Lanjutan dengan Program SPSS. Badan Penerbit Universitas Diponegoro Semarang.

IAI. 2009. Standar Akuntansi Keuangan Per 1 September 2009. Jakarta:Salemba Empat

Januarti, Indira, (2009). "Analisis pengaruh faktor perusahaan, kualitas auditor, kepemilikan perusahaan terhadap opini audit going concern", Universitas Diponegoro.

Jensen, Michael C dan William H.Meckling. (1976), "Theory of the firm" managerial behavior, agency costs and ownership structure", Journal of Financial Economics Vol.3, No.4, pp.305-360.

Kang, Won Sil.,Kilgore, Alan.,Sue Wright. (2011),'The effectiveness of audit committees for low-and-mid-cap firms", Managerial Auditing Journal-Emerald Vol.26 No.7,2011 pp 623-650.

Kieso, Donald E., Jerry J. Weygandt dan Terry D. Warfield. 2011. "Intermediate accounting.IFRS Edition", Vol.1. John Wiley \& Sons, Inc. United States of America.

Klein, April. (2011), "Audit committee, board of director characteristics, and earnings management", Managerial Auditing Journal-Emerald Vol.33. 
Komite Nasional Good Coporate Governance, "Pedoman Pembentukan Komite Audit yang Efektif”. 2006.

Rahman, Rashidah Abdul., Ali, Fairuzana Haneem Mohamed. (2006), "Board, audit committee, culture and earnings management: malaysian evidence", Management Auditing Journal-Emerald Vol 21. Pp. 783804.

Rahmat, Mohd Mohid., Iskandar Takiah Modh., Saleh Norman Mohd. (2009), "Audit committee characteristics in financially distressed and nondistressed companies", Management Auditing Journal-Emerald Vol 24.

Sawyer, B.L., Dittenhofer, M.A., James H. Scheriner, 2003. Sawyer's Internal Auditing-The Practice of Modern Internal Auditing, $5^{\text {th }}$ Edition. United States Of America: Institute of Internal Auditors.

Scott, William. R., 2006, Financial accounting theory, $\mathbf{4}_{\text {rd }}$ Edition. Pearson Prentice Hall. Toronto.

Wang Xia, Min Wu.(2011), "The quality of financial reporting in china: an examination from an accounting", China Journal of Accounting Research-Emerald Vol. 4. 2011. pp167-196.

$\mathrm{Zu}$, Xingxing., Kaynak Hale. (2012), “An agency theory perspective on supply chain quality management", International Journal of Operations \& Production Management-Emerald, Vol. 32.-Pp 423-446

Tiastono Taufan (2011), "Manajemen laba nyata sebagai pemediasi hubungan ukuran kepemilikan institusional dengan kinerja keuangan", Jurnal Ekonomi dan Bisnis Vol.5. 2011.hal 61-73.

www.idx.co.id

www.usatoday.com 


\section{LAMPIRAN}

Nama perusahaan yang melakukan earnings restatement beserta matched sample yang digunakan sebagai sampel dalam penelitian.

\begin{tabular}{|c|c|c|c|c|c|c|}
\hline \multirow[b]{2}{*}{ TAHUN } & \multicolumn{3}{|c|}{ EARNINGS RESTATEMENT } & \multicolumn{3}{|c|}{ MATCHED SAMPLE (UNRESTATED) } \\
\hline & EMITEN & NAMA PERUSAHAAN & $\begin{array}{l}\text { KODE } \\
\text { JASICA }\end{array}$ & EMITEN & NAMA PERUSAHAAN & $\begin{array}{l}\text { KODE } \\
\text { JASICA }\end{array}$ \\
\hline 2010 & BAPA & Bekasi Asri Pemula Tbk & 61 & RBMS & $\begin{array}{l}\text { Ristia Bintang } \\
\text { Mahkotasejati Tbk. }\end{array}$ & 61 \\
\hline 2010 & BIPP & $\begin{array}{l}\text { Bhuwanatala Indah } \\
\text { Permai Tbk }\end{array}$ & 61 & COWL & Cowell Development Tbk & 61 \\
\hline 2010 & BCIP & Bumi Citra Permai Tbk & 61 & LCGP & Laguna Cipta Griya Tbk. & 61 \\
\hline 2010 & CKRA & Citra Kebun Raya Agri Tbk & 61 & GPRA & $\begin{array}{l}\text { Perdana Gapuraprima } \\
\text { Tbk. }\end{array}$ & 61 \\
\hline 2010 & KPIG & $\begin{array}{l}\text { Global Land Development } \\
\text { Tbk. }\end{array}$ & 61 & MDLN & Modernland Realty Tbk. & 61 \\
\hline 2010 & DILD & Intiland Development Tbk. & 61 & ASRI & Alam Sutera Realty Tbk & 61 \\
\hline 2010 & PWON & Pakuwon Jati Tbk & 61 & BKSL & Sentul City Tbk. & 61 \\
\hline 2010 & HITS & $\begin{array}{l}\text { Humpuss Intermoda T. } \\
\text { Tbk. }\end{array}$ & 74 & TRAM & Trada Maritime Tbk & 74 \\
\hline 2010 & RAJA & Rukun Raharja Tbk & 74 & TMAS & $\begin{array}{l}\text { Pelayaran Tempuran } \\
\text { Emas Tbk. }\end{array}$ & 74 \\
\hline 2010 & AGRO & Bank Agroniaga Tbk. & 81 & SDRA & $\begin{array}{l}\text { Bank Himpunan Saudara } \\
1906 \text { Tbk. }\end{array}$ & 81 \\
\hline 2010 & BBKP & Bank Bukopin Tbk. & 81 & $\mathrm{BCIC}$ & Bank Mutiara Tbk. & 81 \\
\hline 2010 & BNBA & Bank Bumi Arta Tbk & 81 & BKSW & Bank Kesawan Tbk. & 81 \\
\hline 2010 & $\mathrm{BABP}$ & Bank Icb Bumiputera Tbk. & 81 & MAYA & $\begin{array}{l}\text { Bank Mayapada } \\
\text { Internasional Tbk. }\end{array}$ & 81 \\
\hline 2010 & BBCA & Bank Central Asia Tbk. & 81 & BNGA & Bank Cimb Niaga Tbk. & 81 \\
\hline 2010 & BNII & Bank Int' L Indonesia Tbk & 81 & BBTN & $\begin{array}{l}\text { Bank Tabungan Negara } \\
\text { (Persero) Tbk. }\end{array}$ & 81 \\
\hline 2010 & BMRI & $\begin{array}{l}\text { Bank Mandiri (Persero) } \\
\text { Tbk. }\end{array}$ & 81 & BBRI & $\begin{array}{l}\text { Bank Rakyat Indonesia } \\
\text { (Persero) Tbk. }\end{array}$ & 81 \\
\hline 2010 & $\mathrm{BBNI}$ & $\begin{array}{l}\text { Bank Negara Indonesia } \\
\text { Tbk. }\end{array}$ & 81 & BDMN & $\begin{array}{l}\text { Bank Danamon Indonesia } \\
\text { Tbk. }\end{array}$ & 81 \\
\hline 2010 & NISP & Bank Ocbc Nisp Tbk. & 81 & MEGA & Bank Mega Tbk. & 81 \\
\hline 2010 & BBNP & $\begin{array}{l}\text { Bank Nusantara } \\
\text { Parahyangan Tbk. }\end{array}$ & 81 & BACA & $\begin{array}{l}\text { Bank Capital Indonesia } \\
\text { Tbk. }\end{array}$ & 81 \\
\hline 2010 & PNBN & Bank Pan Indonesia Tbk. & 81 & BAEK & $\begin{array}{l}\text { Bank Ekonomi Raharja } \\
\text { Tbk. }\end{array}$ & 81 \\
\hline 2010 & BNLI & Bank Permata Tbk. & 81 & BHIT & Bhakti Investama Tbk & 98 \\
\hline 2010 & BTPN & $\begin{array}{l}\text { Bank Tabungan Pensiunan } \\
\text { Nas. Tbk. }\end{array}$ & 81 & INPC & $\begin{array}{l}\text { Bank Artha Graha } \\
\text { Internasional Tbk. }\end{array}$ & 81 \\
\hline 2010 & PNIN & Panin Insurance Tbk. & 84 & MCOR & $\begin{array}{l}\text { Bank Windu Kentjana } \\
\text { International Tbk }\end{array}$ & 81 \\
\hline 2010 & MTFN & Capitalinc Investment Tbk. & 89 & MREI & $\begin{array}{l}\text { Maskapai Reasuransi Ina. } \\
\text { Tbk. }\end{array}$ & 84 \\
\hline 2010 & GSMF & $\begin{array}{l}\text { Equity Development } \\
\text { Investama Tbk. }\end{array}$ & 89 & BCAP & $\begin{array}{l}\text { Bhakti Capital Indonesia } \\
\text { Tbk. }\end{array}$ & 89 \\
\hline 2010 & OKAS & $\begin{array}{l}\text { Ancora Indonesia } \\
\text { Resources Tbk. }\end{array}$ & 91 & TMPI & Agis Tbk. & 91 \\
\hline
\end{tabular}




\begin{tabular}{|c|c|c|c|c|c|c|}
\hline 2010 & TGKA & Tigaraksa Satria Tbk. & 91 & INTA & Intraco Penta Tbk. & 91 \\
\hline 2010 & LPPF & $\begin{array}{l}\text { Matahari Department Store } \\
\text { Tbk. }\end{array}$ & 93 & TRIO & Trikomsel Oke Tbk. & 93 \\
\hline 2010 & MAPI & Mitra Adiperkasa Tbk. & 93 & HERO & Hero Supermarket Tbk. & 93 \\
\hline 2010 & INPP & $\begin{array}{l}\text { Indonesian Paradise } \\
\text { Property Tbk. }\end{array}$ & 94 & MAMI & Mas Murni Indonesia Tbk & 94 \\
\hline 2010 & PANR & $\begin{array}{l}\text { Panorama Sentrawisata } \\
\text { Tbk. }\end{array}$ & 94 & SHID & Hotel Sahid Jaya Tbk. & 94 \\
\hline 2010 & PLIN & $\begin{array}{l}\text { Plaza Indonesia Realty } \\
\text { Tbk. }\end{array}$ & 94 & JSPT & $\begin{array}{l}\text { Jakarta Setiabudi } \\
\text { Internasional Tbk. }\end{array}$ & 94 \\
\hline 2010 & CENT & Centrin Online Tbk. & 97 & INDX & Indoexchange Tbk. & 97 \\
\hline 2010 & MTDL & Metrodata Electronics Tbk. & 97 & ASGR & Astra Graphia Tbk. & 97 \\
\hline 2010 & $\mathrm{MYOH}$ & Myoh Technologi Tbk. & 97 & LMAS & $\begin{array}{l}\text { Limas Centric Indonesia } \\
\text { Tbk. }\end{array}$ & 97 \\
\hline 2010 & BNBR & Bakrie \& Brothers Tbk. & 98 & MLPL & Multipolar Tbk. & 98 \\
\hline 2009 & TLKM & $\begin{array}{l}\text { Telekomunikasi Indonesia } \\
\text { Tbk. }\end{array}$ & 73 & ISAT & Indosat Tbk. & 73 \\
\hline 2009 & INTA & Intraco Penta Tbk. & 91 & OKAS & $\begin{array}{l}\text { Ancora Indonesia } \\
\text { Resources Tbk }\end{array}$ & 91 \\
\hline 2009 & INPP & $\begin{array}{l}\text { Indonesian Paradise } \\
\text { Property Tbk. }\end{array}$ & 94 & MAMI & Mas Murni Indonesia Tbk & 94 \\
\hline 2009 & BNBR & Bakrie \& Brothers Tbk. & 98 & BHIT & Bhakti Investama Tbk & 98 \\
\hline 2008 & LCGP & Laguna Cipta Griya Tbk. & 61 & COWL & Cowell Development Tbk & 61 \\
\hline 2008 & EXCL & Excelcomindo Pratama Tbk & 73 & BTEL & Bakrie Telecom Tbk. & 73 \\
\hline 2008 & BNII & Bank Int' L Indonesia Tbk & 81 & BNLI & Bank Permata Tbk. & 81 \\
\hline 2008 & DKFT & Duta Kirana Finance Tbk & 82 & DEFI & Danasupra Erapacific Tbk & 82 \\
\hline 2008 & ASRM & Asuransi Ramayana Tbk. & 84 & ASDM & $\begin{array}{l}\text { Asuransi Dayin Mitra } \\
\text { Tbk. }\end{array}$ & 84 \\
\hline 2008 & BNBR & Bakrie \& Brothers Tbk. & 98 & BMTR & Global Mediacom Tbk & 98 \\
\hline
\end{tabular}

Keterangan Kode JASICA:

\begin{tabular}{|c|c|}
\hline 61 & : Property and real estate \\
\hline 73 & : Telecommunication \\
\hline 74 & : Transportation \\
\hline 81 & : Bank \\
\hline 82 & : Financial institution \\
\hline 84 & : Insurance \\
\hline 89 & : Others \\
\hline 91 & : Wholesale (Durable \& Non-durable Goods) \\
\hline 93 & : Retail trade \\
\hline 94 & : Restaurant, hotel and tourism \\
\hline 97 & : Computer and services \\
\hline 98 & : Investment Company \\
\hline 98 & : Investment Company \\
\hline
\end{tabular}

